\title{
Longitudinal Research on the Development of Speech of People With Mild Mental Retardation
}

\author{
Jacek J. Błeszyński \\ Nicolaus Copernicus University in Toruń, Toruń, Poland
}

\begin{abstract}
The research on the development of speech of people with mental retardation is one of the areas which are rarely undertaken. The problem applies to both publishing the findings of the research in terms of age, which are rare and outdated and these conducted in line with the approach of the developmental psychology. One of the developmental psychology approach representatives in Poland was Maria Przetacznikowa-Jarża, who in her work, presented a wide spectrum of language competence acquisition on different stages of development. The problem has been also discussed from various angles by Reed, who multi-facetedly analyses communication process. In the case of speech therapy, the current approach to the development of speech of people with varying degrees of mental retardation is associated with oligophreno-logopedics, which most often is recognized as clinical speech therapy section dealing with the diagnosis and treatment of speech disorders - delayed speech development, speech disorders, and language competence occurring in individuals with intellectual disability.
\end{abstract}

Keywords: speech, language, speech, intellectual disability, forms of expression

\section{Introduction}

Other definitions also narrow the issue and scope of activities undertaken in the context of working with people with intellectual disability, as well as the very essence of communication (eg., Skorek, 2005, p. 117). The author of this paper has carried out that studies clearly showing that in such a system of cognitive functioning mental retardation is not a lack, a limitation, but a different system of perception, processing, and creation of cognitive structures (including concepts) and communication as an image reflected in existing reality, which is processed individually in every mind (Błeszyński, 2013, pp. 115-116).

In such a approach, which limts the understanding oligophreno-logopedics-speech therapy for people with intellectual disabilities, as a section of speech therapy dealing with the speech of mentally handicapped individuals-becomes narrow and not entirely structured. As the author of this paper pointed out in his publications, individuals with a formal diagnosis of intellectual disability are classified as members of this group (on the basis of tests and diagnostic proces), but frequently they do not show an organic defect. These individuals are either neglected children (who suffered lack of stimulation, e.g., care resulting from environmental factors or educational neglect), or mentally retarded individuals sufferring from Fragile $\mathrm{X}$ Chromosome Syndrome, autism as undiagnosed (in particular incorrectly diagnosed) (Grenser, Rorman, \& Child, 2007, pp. 567-572). 
As the author indicated in the earlier publications, it is necessary to review that very term (there is a trend to stop using branding terms, derived from biology and medicine), and clarify the scope of the created concept. Oligophreno-logopedics - communication of people with intellectual disabilities/mental retardation is a range of actions (diagnosis, therapy, and support), speech therapy, undertaken using the methods research aimed at determining the optimal functioning of the tested person, and on this background, to assess the development of communication, speech, and language, and indications of irregularities occuring in the communication process (Błeszyński, 2015a, p. 166). Extending the research to communication, and not as before narrowing to speech and language, allows for a multi-faceted understanding of the entire process of acquisition of communication and language skills as historically presented by Grenser, Rorman, and Child (2007, p. 63).

An important element of supportive and therapeutic procedure is the goal set for undertaken actions. While showing multidirectional possibilities of placing a disabled person in the modern world, not only the effect but also possibilities, needs, treatment, and social conditions are equally important. The approaches to individuals with disabilities presented by the author of this work in earlier publications (Błeszyński, 2015b, pp. 12-16) describe three trends, each of which determines the place of of a disabled person in a social structure.

It is also a determinant of speech therapist's therapeutic work, which becomes a part of interaction aimed at facilitating and finding a place for individuals with intellectual disabilities in society. In his research, the author especially pays attention to the optimization problem (Błeszyński, 2010, pp. 25-30), as rationalization, modification, evaluation, stimulation, strengthening — but above all adaptation of the requirements and purpose, to the needs and possibilities of the individuals undergoing therapy.

\section{Literature Review}

As shown by numerous sources, it is possible to provide a full etiology of mental retardation, and thus, the factors affecting the development of communication. At this level, an important division, was made by Styczek (1979), dividing factors to endogenous and exogenous. As factors that influence the development of communication, and in particular, speech, Jęczeń (2003) mentioned:

1. Immaturity (including a delay myelination of nerve fibers) or damage to the nervous system;

2. Morphological defects and malfunctions articulatory apparatus (Duffy, 2013);

3. Insufficiently formed dominance of one hemisphere of the brain leading to abnormal lateralization;

4. Emotional disturbance;

5. Hyperactivity or apathy;

6. The occurrence of characteristic forms of mental retardation (down syndrome, micro-cephaly, cerebral palsy, and focal damage to the left hemisphere of the brain) (pp. 127-138).

At this point, however, arises a need of discussion whether down syndrome, cerebral palsy, as well as focal damage to the left hemisphere of the brain are factors affecting incidence of mental retardation. It can be considered that such a relationship does not have to coincide, but certainly conditional mental impairment does not need to occur in these cases. Such popular approaches to disability and certain genetic diseases recognized as determining mental development have been undermined, and evolve in the direction of finding the optimum forms of assistance, rehabilitation - which we understand, not as a restoring skills (It is difficult to restore something that never existed), but shaping them. 
The approach to the problem of intellectual disability, and in particular, the development of speech and language has been transformed and redefined. This applies both to tests conducted at the theoretical level (Krzemińska, 2012; Wątorek, 2014) as well as practical (Malczyk, 2006, pp. 98-104). An important publication, which presents psycho-lingual approach to the language of a child with a disability is the study of the Reed (2012, pp. 229-270). In the discussion over the development of social skills, especially communication the author of this article contributes by presenting his research, which can primarily fill the gap in research reports, as well as present many areas, which in the case of speech therapy urgently need to be analysed and described.

\section{Assumptions Connected with Conducting the Research}

The study concerned the speech of individuals with mild mental retardation mild, widened subsequently to the comparison with a group of high school students within the intellectual norm, and pointed at the essential elements not only differentiating, but also indicating different features of acquisition of skills related to communication, and an emerging style of thinking. Moving away from simple binding of speech disorders (communication and language) with intellectual disabilities has become important, and consequently, leads to a need to change the approach for all degrees of mental retardation.

The earlier research results concerned with the language skills of individuals with mild mental retardation (Błeszyński, 2014, pp. 39-56) were then compared with those of their peers from public schools (Błeszyński, 2013). The next stage of the research carried out at the University of Nicolaus Copernicus, was to conduct the analysis of utterances of children with mild intellectual disability on five levels, three stages of education, i.e., preschool, primary school (Grades I-II and IV-VI), middle school, and upper secondary education. Tasks were chosen to get the most comparable results. The number of people conducting the experiment was limited to a minimum.

The biggest difficulty was the selection of a research group of preschool children, which was related to the varied delays in speech development, environmental neglect, and mental retardation. The test results were obtained in cooperation with family environment and schools assuming that in the coming years will be to make a final verification of the etiology of generated disorders. In total, the study involved 160 children and adolescents aged from kindergarten to secondary school, and 40 persons in each group (see Table 1).

Table 1

The Number of Participants Involved in the Study at Different Levels of Education

\begin{tabular}{ll}
\hline Stage of education & Number of persons undergoing the research \\
\hline Preschool & 40 \\
Primary school & 40 \\
Middle school & 40 \\
Upper secondary education & 40 \\
\hline
\end{tabular}

Note. Source: Own research.

The research was conducted in Kuyavian-Pomeranian, often re-used by teachers and speech therapists to assess children's development. The study aimed not only at acquiring data, but maintaining a closer cooperation with the local community, an indication of the practical dimension of the analyzes performed and the need to start collaboration between university theoreticians and practitioners. The research is ongoing, and in this article, the preliminary results have been presented which will be replenished later. The study started in 2013 and the expected date of completion is 2016. 


\section{The Results of the Research}

In the course of the study, efforts were made to preserve the task force situation. There were no rewards used, no competition was introduced. The author desired to conduct the research in natural situations that are familiar and daily for a child.

The hardest part was to gather a group of preschool children, which was closest to the developmental age of peers. Along with the subsequent stages of education, the age difference in relation to peers attending the class increased, i.e., a delay or postponement from compulsory schooling, and second year in the same grade (see Table 2).

Table 2

The Use of Parts of Speech to Describe the Image at Different Stages of Education

\begin{tabular}{|c|c|c|c|c|}
\hline & \multirow{2}{*}{ Preschool } & \multicolumn{2}{|c|}{ Primary school } & \multirow{2}{*}{ Middle school } \\
\hline & & I-III & IV-VI & \\
\hline Noun & 1,167 & 1,195 & 906 & 563 \\
\hline Adjective & 47 & 189 & 163 & 105 \\
\hline Verb & 400 & 960 & 397 & 347 \\
\hline Participle & 0 & 0 & 18 & 8 \\
\hline Numeral & 0 & 12 & 22 & 24 \\
\hline Pronoun & 60 & 167 & 155 & 187 \\
\hline Adverb & 233 & 355 & 26 & 94 \\
\hline Preposition & 7 & 0 & 261 & 212 \\
\hline Prepositional phrase & 0 & 0 & 211 & 164 \\
\hline Conjunction & 0 & 628 & 118 & 127 \\
\hline Particle & 173 & 101 & 18 & 22 \\
\hline Average & 189.73 & 327.91 & 208.64 & 168.45 \\
\hline
\end{tabular}

Note. Source: Own research.

Dominant trends in the findings of the research:

1. The increasing number of used numerals along with the growing age of the subjects of the research.

2. Decreasing number of used nouns, adverbs, and particles.

3. The emergence of the use of conjunctions and the number of prepositional phrases, and then, decreasing in the first stage of education - in classrooms of primary education.

4. Intensifying the occurrence and then decreasing numbers of the used verbs, pronouns, and adjectives in the first stage education - in classrooms of primary education.

5. These trends are very clearly visible on the graph, which allows us to analyze the use and coexistence of the parts of speech at the various stages of education.

It is also important to draw attention to the parts of speech that are not subject to important evaluation during all stages of education, e.g., participles, numerals, and pronouns. The biggest differences are in the use of nouns, verbs, and adverbs.

In the case of primary school educational stage, in particular Classes I-III should be considered a milestone (see Figure 1).

The study also included mistakes in the statements, which were formulated by the surveyed students (see Table 3). In written statements lexical—phraseological mistakes do not occur (they were not reported). The most common mistakes were spelling mistakes (not properly acquired rules). 


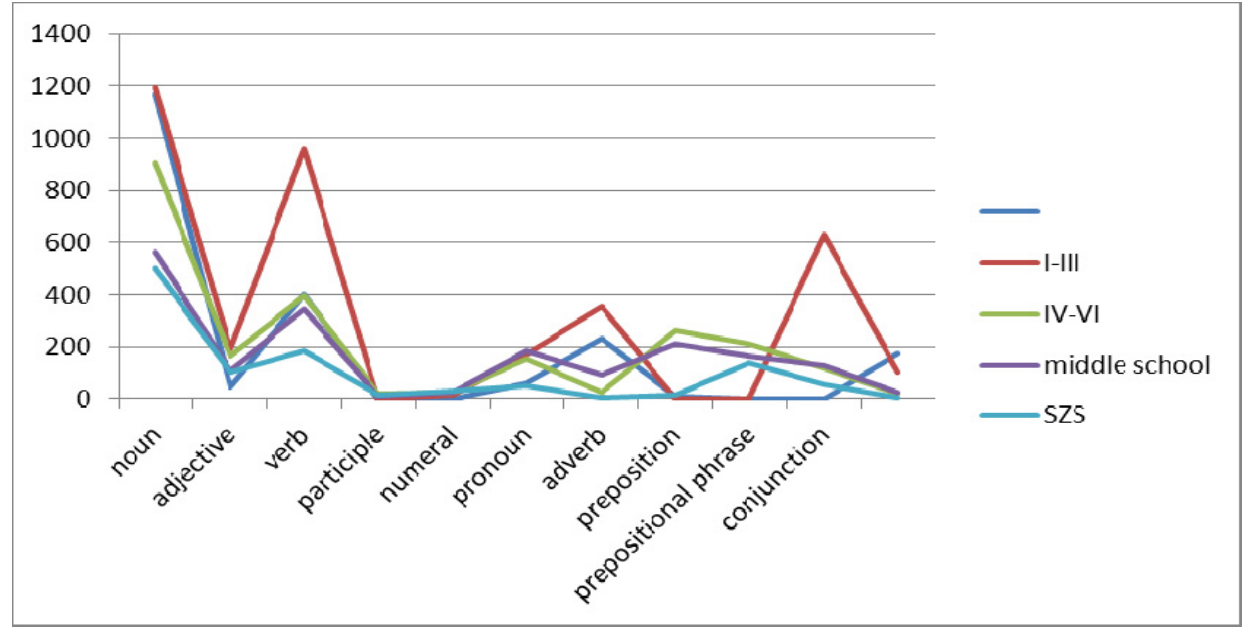

Figure 1. The use of parts of speech to describe an image at different stages of education. (Source: Own research)

Table 3

Mistakes Made in the Statements Written by the Surveyed Students [N $=120]$

\begin{tabular}{lccc}
\hline & Primary school & Middle school & Vocational school \\
\hline Grammar: Inflexional & 127 & 62 & 40 \\
Grammar: Syntactic & 19 & 43 & 19 \\
Lexical vocabulary & 0 & 0 & 3 \\
Lexical word formation & 5 & 3 & 2 \\
Stylistic & 184 & 114 & 61 \\
Spelling & 541 & 211 & 145 \\
Punctuation & 381 & 214 & 147 \\
Average & 157.13 & 80.875 & 52.125 \\
\hline
\end{tabular}

Note. Source: Own research.

These errors can be grouped. The least frequent are lexical errors, which are characterized by similar levels of severity. The next type are grammatical errors (severe inflexional mistakes of students in Grades IV-VI of primary school). The most severe stylistic, punctuation, and spelling - the highest level in Classes IV-VI of primary school (see Figure 2).

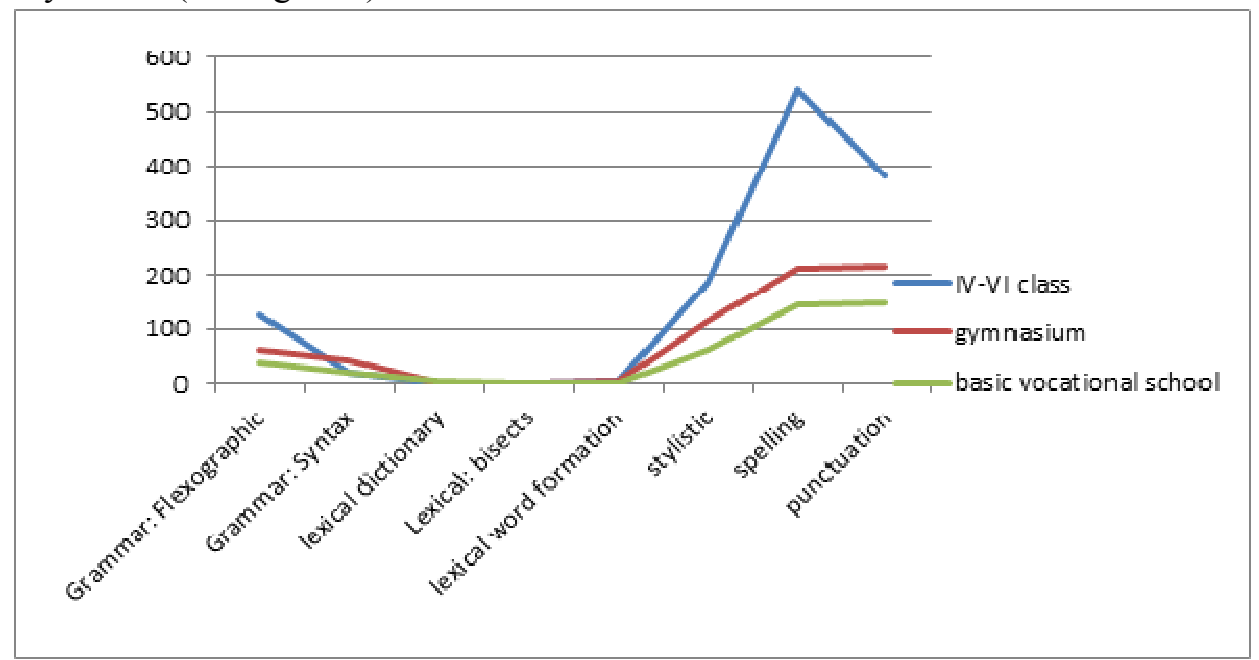

Figure 2. Mistakes made while describing an image at different stages of education. (Source: Own research) 


\section{Discussion and Conclusion}

The studies are related to the theories and concepts of speech formation. One of these, despite being undermined and still recognised allows to conduct deeper analyzes is the theory of Benjamin Lee Whorf, presented in Język, myśl i rzeczywistość (language, mind, and reality) published also in Polish in 2002. In addition to previous observations, discussions presented in the magnificent work of Klimchuk (2013), the author of this work has ommitted a number of controversial aspects, but draws the attention to an important statement of Benjamin Lee Whorf presented in Chapter Geometria reguł. Formjęzyk (Whorf, 2002) of his publication. According to Whorf, such an arrangement comes from outside the narrow circle of individual consciousness; as a result of it, an individual becomes a puppet, whose linguistic maneuvers are determined by an impalpable and tight, but cohesive pattern (2002, p. 343). In this chapter, Whorf drawn the attention to the social character of language (as many other psychologists) and speculative equivocal influence on shaping language competence of an every human being. Language competence is not only a socially important progress, but a responsibility and factors influencing acquiring it. Language is a social creation, and as such, undergoes multidimensional, functional, and conditional modifications typical for an every individual.

This has further consequences connected with the issue of speech of intellectually disabled persons raised by the author of this article. It must be assumed that communication, as a social creation, however, is conditioned by the human factor. Society is one of the factors that can develop or limit the development of, in particular, communication, speech, and language of an individual. This social character of the formation of communication skills, is becoming one of the opportunities to develop other functions. As noted by Lee Whorf, there is a differentiation in language acquisition, which can be looked at not only through the prism of intelligence quotient (IQ), but the acquisition of communication skills-nowadays commonly referred to as language proficiency. This development of features, skills not only aims to expand the acquired knowledge, but above all, its use of at a higher level of correlation. This development of features and skills not only aims to expand the acquired knowledge, but above all, its use of at a higher level of correlation. Higher mind is a systematic and configurative, and thus, the standard language aspect controlsits aspect of, "lexation," or naming. The meanings of the words are less important than we usually think. The essence of the of speech are not words, but sentences just like the math content is not numbers, but the equations and functions (Whorf, 2002, p. 345).

Similarly, in the development of analysis in children and adolescents, and broader research on individuals with mild mental retardation, it becomes significant not to use only quantitative analysis of particular parts of speech, but also:

1. The role of the individual parts in the creation of an utterance and their impact on the accuracy of expression;

2. Order and variability of occurrence (appearance and evaluating) parts of speech in the statements, which is dynamic and developmental (studied by developmental psychologists);

3. The importance of social utility built of an utterance as a means of delivering maturing thoughts and structures of thought;

4. The search for conditions, which influence the improvement of communication and linguistic skills compared with:

(1) Non-disabled peers;

(2) At different levels of development—education (as educational programmed skills development); 
(3) The impact of increased stimulation of the environment as institutionalized (special education) and the influence of peers and mass education system requirements;

(4) The occurrence of errors at the level of verbal and expressive of spoken utterances - as reflecting mechanisms for creating and transforming the content of speech.

At this stage of the study, it can be concluded that the first and second stage of education are groundbreaking, because then there is an increase of trends in the occurrence of errors- the most common being stylistic, punctuation, and spelling.

The difficulties that arise are multilateral. First of all, they occur during puberty and the process of development of personality - this can be reflected in the intensity of attention to the content, thought, less so form.

The conducted research aims to present the studies, so far abandoned, aimed to determine the ability to use the language in a number of areas:

1. Developmental (developmental psychology, speech therapy, and educational), the state of speech and language development on three stages of education;

2. Clinical (special education, oligophreno-logopedics—-speech therapy for people with intellectual disabilities) speech development of disabled persons with global developmental disorders;

3. Differentiation (educational speech therapy and linguistics), presenting the characteristic changes in the development of speech of people with mild intellectual disability.

As shown by studies conducted in other countries, e.g., the study of Cirrin and Gillam (2008, pp. 132-133), pointed out that schools are required to create special educational interactions (services) that require monitoring student progress on all levels of development. It is difficult to confirm clearly the correlation (language-achieved educational results). This is particularly important in the work with students with intellectual disabilities.

\section{References}

Błeszyński, J. J. (2010). Discriminating analysis of selected bands autism. In Outline of revalidation. UMK, Toruń.

Błeszyński, J. J. (2013). Intellectual disability: Speech, language, communication. Does IQ explain everything? Harmonia, Gdańsk.

Błeszyński, J. J. (2014). Language of people with mild intellectual disability—An independent research taking written statements. In A. Hamerlińska-Latecka, \& M. Karwowska (Eds.), Interdisciplinarity in speech therapy. Fundacjadla Uniwersytetu Kazimierza Wielkiego, Komlogo Piotr Gruba, Gliwice.

Błeszyński, J. J. (2015a). Diagnostic and therapeutic proceedings in speech therapy. In K. Kaczorowska-Bray, \& S. Milewski (Eds.). Harmonia Universitas, Gdańsk.

Błeszyński, J. J. (2015b). Disability, incomplete performance, efficiency and perhaps other. Ateneum Kapłańskie, ZESZYT, 1(635); styczeń/luty, TOM, 164, 8-16.

Cirrin, F. M., \& Gillam, R. B. (2008). Language intervention practices for school-age children with spoken language disorders: A systematic review. Language, Speech, And Hearing services in Schools, American Speech-Language-Hearing Association, $39,110-137$,

Duffy, J. R. (2013). Motor speech disorders: Substrates, differential diagnosis and management. Elsevier, St. Louis.

Grenser, J., Rorman, B., \& Child, T. (2007). Speech and language deficits in children with developmental disabilities. In J. W. Jacobsor, J. A. Mulick, \& J. Rojahn (Eds.), Handbook of intellectual and developmental disabilities. Springer.

Jacobsor, J. W., Mulick, J. A., \& Rojahn, J. (2007). Handbook of intellectual and developmental disabilities. Springer.

Jęczeń, U. (2003). Conditions for development of language and communicative competence in children with mental disabilities. Logopediat.32, podred. Stanisława Grabiasa, 127-138.

Klimczuk, A. (2013). Linguistic relativity Sapira-Whorfa-A review of the arguments of supporters and opponents. Kultura, Społeczeńs Two, Edukacja, 1(3), 165-178. 
Krzemińska, D. (2012). Language and discourse of everyday people with intellectual disabilities. Impuls, Kraków.

Kupisiewicz, M. (2014). Dictionary of special education. APSiWNP, Warszawa.

Malczyk, G. (2006). Using knowledge of foreign language teaching in dealing with children with learning disabilities in varying degrees. Logopedia, 1-2, 98-104. Retrieved from http://www.logopeda.org.pl/resources/pliki/65_logopeda_nr_2.pdf, 13.02.15

Reed, V. A. (2012). An introduction to children with language disorders. Pearson, Soston.

Skorek, E. M. (2005). With speech therapy for you. In Concise dictionary. Impuls, Kraków.

Styczek, I. (1979). Logopedia. PWN, Warszawa.

Wątorek, A. (2014). Language competence of students with mild intellectual disability. NOMOS, Kraków.

Whorf, B. L. (2002). Language, thought and reality. K.R., Warszawa.

Whorf, B. L. (1956). Language, thought, and reality: Selected writings of .... In J. B. Carroll (Ed.). Oxford, England: Technology Press of MIT. 